\title{
Analisa Lifetime Katalis pada Reaktor Fix Bed di Catalytic Condensation Unit Light End Unit
}

\author{
Yully Mulyani ${ }^{(1, a) *}$ dan Ivan Fadila ${ }^{(2)}$ \\ ${ }^{(1,2)}$ Prodi Diploma-III Teknik Kimia, Akademi Minyak dan Gas Balongan, Indramayu, Indonesia, 45216 \\ Email : ${ }^{\left(a^{*}\right)}$ yullymulyani@gmail.com
}

Diterima (25 November 2021), Direvisi (31 Desember 2021)

\begin{abstract}
The refinery configuration is focused on converting the dominant residue content in heavy crude oil into more valuable products. Light End Unit (LEU) is a secondary processing which is built to process top product from main column in Residue Catalytic Cracking $(R C C)$ unit. In LEU there are 5 units, one of which is Unit 20 Catalytic Condensation Unit (CCU). Unit 20 processes Butane mix from Unit 19 Propylene Recovery Unit (PRU) and produces the main product polygasoline with a high octane number. Another product produced is butane for LPG blending. In the CCU unit there are 3 reactors which are where the polymerization reaction occurs which is assisted by a catalyst, the reactor used is of the Fix Bed Reactor type which means the catalyst remains in the reactor, and at any time the catalyst can be deactivated. It was found that the average polygasoline production was still below the design with the average end point value of polygasoline products of $201^{\circ} \mathrm{C}$ with the maximum condition being $205^{\circ} \mathrm{C}$. The average $R O N$ is $>100$ with a minimum requirement of 98 , the average RVP is 6.06 Psig for a maximum RVP requirement of 6.5 Psig. the latest data obtained lifetime of $0.124 \mathrm{~m}^{3} / \mathrm{kg}$ from a design of $0.75 \mathrm{~m}^{3} / \mathrm{kg}$, with the results of the lifetime of the catalyst the condition of the catalyst is still good and has not been deactivated so that there is no need to replace the catalyst.
\end{abstract}

Keywords: Reactor, Polymerization, Lifetime catalyst, Polygasoline

Abstrak. Konfigurasi kilang difokuskan pada pengubahan kandungan residu yang dominan pada minyak mentah berat tersebut menjadi produk-produk yang lebih berharga. Light End Unit (LEU) merupakan secondary processing yang dibangun untuk mengolah top product dari main column pada unit Residue Catalytic Cracking (RCC). Dalam LEU terdapat 5 bagian unit salah satunya Unit 20 Catalytic Condensation Unit (CCU). Unit 20 ini mengolah Butane mix dari unit 19 Propylene Recovery Unit (PRU) dan dihasilkan produk utama polygasoline dengan angka oktan yang tinggi. Produk lainnya yang dihasilkan adalah butane untuk blending LPG. Dalam unit CCU terdapat 3 reaktor yang merupakan tempat terjadinya reaksi polymerisasi yang dibantu oleh katalis, Reaktor yang digunakan bertipe Fix Bed Reactor yang berarti katalis tetap berada didalam reactor, dan sewaktu - waktu katalis dapat mengalami deaktivasi. Didapatkan rata-rata produksi polygasoline masih dibawah design dengan rata-rata nilai end point dari produk polygasoline sebesar $201^{\circ} \mathrm{C}$ dengan syarat maksimal adalah $205^{\circ} \mathrm{C}$. Rata-rata RON adalah >100 dengan syarat minimal 98, rata-rata RVP adalah 6,06 Psig untuk syarat RVP maksimal 6,5 Psig. Berdasarkan hasil analisa lifetime katalis pada reactor fix bed diperoleh lifetime katalis angka terakhir menunjukan $0,124 \mathrm{~m}^{3} / \mathrm{kg}$ dari lifetime design $0,75 \mathrm{~m}^{3} / \mathrm{kg}$, dengan hasil lifetime katalis tersebut kondisi katalis masih bagus dan belum mengalami deaktivasi sehingga belum perlu dilakukan penggantian katalis.

Kata kunci: Reaktor, Polimerisasi, Lifetime katalis, Polygasoline 

Yully Mulyani: Analisa Lifetime Katalis Pada Reactor Fix Bed
di Catalytic Condensation Unit Light End Unit
Jurnal Migasian, e-issn : 2615-6695 / p-issn : 2580-5258

\section{PENDAHULUAN}

Indonesia merupakan konsumen terbesar produk bahan bakar fosil yang cukup tinggi, Seiring dengan berjalannya waktu kebutuhan Bahan bakar minyak (BBM) di Indonesia meningkat, terutama kebutuhan BBM dengan oktan yang lebih tinggi. Hal ini terjadi karena spesifikasi mesin dengan teknologi terbaru yang menuntut BBM yang lebih berkualitas.

Catalytic condensation unit merupakan bagian dari Light End Unit. Proses pengolahan fraksi ringan (light end) adalah pemisahan fraksi menjadi komponenkomponen yang tidak dapat dilakukan pada tekanan atmosfir, sehingga dilakukan pada tekanan vakum. Proses ini menggunakan paten dari Universal Oil Product (UOP). Secara fisis bahwa apabila suatu zat cair maupun gas bila tekanan dipermukaan dinaikkan maka gas atau zat cair tersebut titik didihnya akan naik, sehingga dasar tersebut yang digunakan proses light end. [1]

Catalytic Condensation Unit terdapat 3 reaktor yang berjenis Fix Bed Reactor. Dalam fix bed reactor pelet - pelet katalis berada disuatu tempat dan tidak bergerak berdasarkan kerangka acuannya. Material dan keseimbangan energi diperlukan untuk kedua fluida yang menempati bagian diantara Partikel - partikel katalis dan reaksi terjadi pada partikel - partikel katalis tersebut [3]. Katalis yang berada di dalam reaktor sewaktu waktu akan mengalami kerusakan atau deaktivasi, oleh karena itu dilakukan evaluasi dan analisa lifetime selama satu bulan.

Terjadinya deaktivasi ini tentu merupakan proses yang kurang menguntungkan secara ekonomis sehingga efeknya harus diminimalkan. Bermacam teknologi dibuat untuk meminimalkan deaktivasi katalis sehingga katalis tidak perlu sering diregenerasi. Beberapa penyebab terjadinya deaktivasi katalis adalah sebagai berikut:
a. Pengotoran (fouling)
b. Peracunan (poisoning)
c. Penggumpalan (sintering) [1]
Polygasoline merupakan salah satu produk utama dari Catalytic Condensation Unit yang bernilai oktan tinggi. Untuk menghasilkan produk yang memiliki oktan tinggi, diperlukan reaktor untuk mereaksikan bahan baku dengan bantuan katalis yang memenuhi standar. Sewaktu - waktu kinerja katalis dapat berkurang karena digunakan dalam waktu yang lama pada reaktor, sehingga diperlukan penggantian katalis secara rutin.

Tujuan dari penelitian ini menganalisa lifetime katalis pada reactor fix bed untuk menghasilkan produk yang memiliki oktan tinggi dari Catalytic Condensation Unit yang mengolah $\mathrm{C} 4$ mixed menjadi produk utama berupa Polygasoline dan Butane

\section{Catalytic condensation unit}

Unit Proses Catalytic Condensation adalah unit proses lanjutan dari Propylene Recovery Unit yang bertujuan untuk memproses Butane Mix supaya dihasilkan produk utama yaitu Polygasoline dengan berat molekul yang tinggi dan menggunakan katalis SPA (Solid Phosphoric Acid) untuk proses Polymerisasi, yang merupakan suatu reaksi eksotermis dimana molekul-molekul olefine bergabung. Disamping itu ada produk lain yaitu Butane yang digunakan sebagai komponen blending LPG. Selain terjadi reaksi penggabungan juga diikuti proses / reaksi perengkahan. Proses unit yang dirancang oleh Universal Oil Product (UOP) ini merupakan proses yang sederhana, tidak rumit dan sangat efisien untuk memproduksi gasoline kualitas tinggi [5] 


\section{Reaktor}

Jenis reaktor yang digunakan dalam Catalytic condensation unit. Reaktor - reaktor tersebut digunakan tergantung dari kondisi operasi yang diinginkan, masing-masing reaktor juga memiliki kelebihan dan kekurangan masing-masing.

\section{1) Chamber Reaktor}

Jika katalis yang digunakan dalam jumlah banyak maka reaktor ini merupakan pilihan yang terbaik. Salah satunya dikarenakan proses pergantian katalis cukup mudah pada reaktor ini. Panas yang terjadi di dari reaksi eksotermis melalui multi bed reaktor didinginkan oleh quenching saturated LPG sehingga fasilitas steam generation tidak ada seperti di tubular reaktor. Combine feed dalam reaktor ini dibatasi 25\% - 30\% senyawa olefin agar temperatur di dalam reaktor tetap terjaga. Chamber reactor memerlukan energi yang tinggi untuk operasi unit tetapi yang terpenting capital cost lebih rendah dibandingkan tubular reaktor.

\section{2) Tubular Reaktor}

Reaktor ini dapat dioperasikan untuk combine feed yang mengandung senyawa olefin sampai 50\%. Bila pyrolysis olefinnya $85 \%$ - 95\% senyawa olefin, diperlukan LPG recycle untuk mendapatkan konsentrasi olefin pada feed turun sekitar 50\%. Panas yang terjadi karena reaksi eksotermis pada reaktor ini dimanfaatkan untuk membuat steam.

Reaktor jenis ini umumnya digunakan untuk penggunaan katalis dalam jumlah yang sedikit yaitu sekitar $2-10 \mathrm{~m}^{3}$. Reaktor jenis ini akan mengalami kesulitan dalam proses pergantian katalis khususnya jika katalis sudah menggumpal dan mengeras. Keuntungan dari reaktor ini adalah tekanan reaktor sintesis bisa lebih tinggi dari chamber Reaktor.Sistem pendingin dari reaktor ini lebih sederhana dari chamber reactor yang menggunakan sistem pendingin quenching. Sistem pendinginnya menggunakan kondensat yang menyelubungi bagian terluar sehingga dapat juga digunakan dimanfaatkan sebagai steam generator. Akibat tidak menggunakan quenching maka konsentrasi olefin di dalam reaktor tidak dapat diatur sesuai keinginan. Umur katalis reaktor ini lebih panjang dari pada chamber reactor. [5]

\section{Katalis Solid Phosporus Acid (SPA)}

Katalis adalah senyawa atau zat yang dapat menaikkan kecepatan reaksi kimia dimana senyawa atau zat tersebut tidak ikut bereaksi secara permanen [6] UOP memperkenalkan dua jenis katalis SPA (Solid Phosphoric Acid), yaitu SPA 1 dan SPA 2 yang mempunyai karakteristik yang sama kecuali ukuran dan penggunaannya. SPA 1 diameternya lebih besar dan digunakan di Reaktor Chamber. SPA 2 diameternya lebih kecil dan digunakan di Reaktor Tubular.

Katalis SPA dihasilkan dari campuran 60 $\%$ wt Phosphoric Acid (sebagai $\mathrm{P}_{2} \mathrm{O}_{5}$ ) dengan $40 \%$ wt Silica Oxide ( $\mathrm{SiO}_{2}$ ) yang terbentuk secara alami yang dinamakan Diatomaceous Earth (Kieslguhr, Infusorial Earth), berupa kristal silika phosphate dan bentuk amorf dari asam fosfor, dimana dalam pencampuran ini dikontrol temperatur dan kelembabannya didalam tungku yang berputar menjadi bentuk extruded atau silinder. Bagian yang aktif atau bagian asam yang ada dalam katalis SPA dinamakan Free $\mathrm{P}_{2} \mathrm{O}_{5}$ ( Asam Fosfor Bebas ) yaitu jumlah asam yang keluar dari katalis pada saat butir atau kelompok katalis dijatuhkan dalam air dingin, kemudian air tersebut di test secara analitik dengan cara titrasi untuk menentukan kandungan asam. Jumlah asam fosfor yang aktif tergantung pada kandungan moisture dalam katalis, disamping itu keaktifan katalis ditentukan juga oleh struktur pori katalis. Bila tingkat hidrasi Free $\mathrm{P}_{2} \mathrm{O}_{5}$ rendah karena katalis dikeringkan dibawah tingkat hidrasi pabrik, maka pertama-tama aktifitas akan naik dan 


\section{Yully Mulyani: Analisa Lifetime Katalis Pada Reactor Fix Bed di Catalytic Condensation Unit Light End Unit \\ Jurnal Migasian, e-issn : 2615-6695 / p-issn : 2580-5258}

selanjutnya akan menurun sejalan dengan berkurangnya kandungan asam. umur katalis ditentukan oleh kemampuan mencapai konversi yang diinginkan dan naiknya pressure drop reaktor yang diperbolehkan. [5]

Beberapa faktor yang menurunkan keaktifan katalis:

1. Penumpukan coke dalam katalis.

Karena terbentuknya heavy polimer yang menutupi bagian sisi yang aktif dari katalis.

2. Perubahan bentuk katalis.

Kurangnya aliran distribusi dalam reaktor karena tingginya pressure drop, sehingga keaktifan katalis yang digunakan menjadi rendah dan berubah bentuk karena panas yang tinggi.

3. Kurang tepatnya hidrasi katalis.

Tingkat hidrasi katalis yang kurang atau berlebihan akan menurunkan keaktifan, dimana secara dramatis perubahan level.

Berikut ini Sifat-sifat physics \& kimia beberapa katalis yang dapat dilihat pada tabel 1[4]:

Tabel 1. Sifat-sifat physics \& kimia katalis

\begin{tabular}{|c|c|}
\hline Tipe katalis & SPA 1 \\
\hline $\begin{array}{l}\text { Ukuran Nominal (diameter } \mathrm{x} \\
\text { panjang , mm }\end{array}$ & $6 \times 9$ \\
\hline Free Phosphoric Acid, \% wt & $16-20$ \\
\hline Total Phosphoric Acid, \% wt & $60-65$ \\
\hline Temperatur Operasi, ${ }^{\circ} \mathrm{C}$ & $150-225$ \\
\hline Average Bulk Density, Ibs / $\mathrm{ft}^{3}$ & $54-64$ \\
\hline $\begin{array}{l}\text { Catalyst life (Ib/ gal polygasolyne } \\
\text { product) }\end{array}$ & 110 \\
\hline Crush strangeth, Ibs & $18 \mathrm{~min}$ \\
\hline
\end{tabular}

\section{Reaksi Yang Terjadi}

Catalytic Condensation Unit merupakan unit yang mempunyai suatu reaksi polymerisasi dari senyawa olefine (propylene, butylene) menjadi produk dengan berat molekul yang tinggi dan menggunakan katalisator Solid Phosphoric Acid ( SPA ).

Hasil reaksi polymerisasi ini sangat kompleks karena terbentuk dari penggabungan bermacam - macam isomer. Disamping itu juga terjadi reaksi perengkahan yang boleh dikatakan relatif kecil.

Produk hasil reaksi polymerisasi (Oligomer) tergantung pada komposisi feed stock terutama konsentrasi propylene dan butylene. Reaksi polymerisasi yang berlanjut akan membentuk Heavy Carbonated material yang akan menempel dan menumpuk pada katalis sehingga keaktifan katalis menurun, oleh karena itu perlu dilakukan penggantian katalis secara periodik ( \pm 3 bulan sekali ).

Reaksi polymerisasi dan perengkahan sebagai berikut :

Reaksi Polymerisasi :

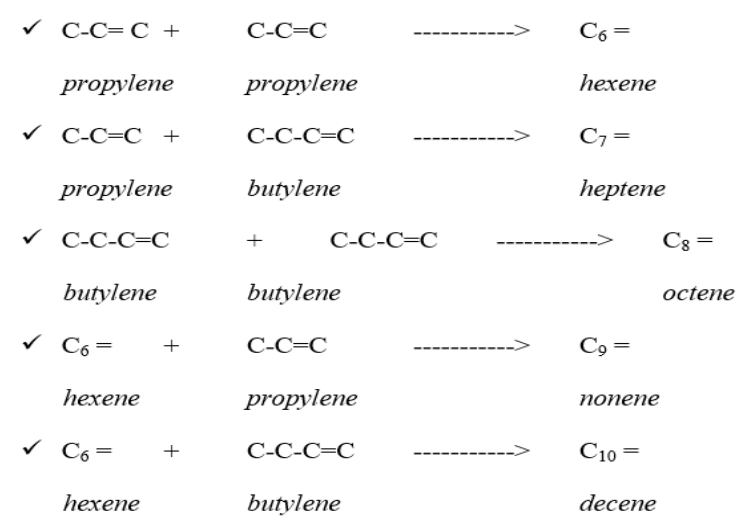

Reaksi Cracking ( perengkahan )

$$
\begin{array}{lll}
\mathrm{C}_{14}= & \mathrm{C}_{9}= \\
\text { Tetradecene } & - & \mathrm{C}_{5}=+-->\mathrm{C}_{7}=+
\end{array}
$$

\section{Perhitungan Lifetime Katalis}

a. LHSV ( Liquid Hourly Space Velocity) LHSV adalah perbandingan volume per 
jam antara reactor feed dengan volume katalis didalam reaktor.

$L H S V=\left(\frac{\left(\frac{\text { Feed Reactor Fresh }}{\text { SG Feed Fresh }}\right)+\left(\frac{\text { Feed Reactor Recycle }}{\text { SG Feed Recycle }}\right)}{\text { Volume }}\right)$

\section{b. Persen Feed Olefin}

Rumus yang digunakan untuk menemukan persen olefin total dari feed yang masuk kedalam reaktor. Langkah pertama adalah mencari persen olefin fresh masing-masing komponen dengan menggunakan beberapa data yang diperoleh dari laboratorium seperti persen olefin produk secara lab, Mol Weight total data laboratorium dan BM masing-masing komponen dengan menggunakan rumus:

Persen Fresh $\mathrm{A}=\left(\frac{\mathrm{BM} \mathrm{A}}{\text { Mol Weight Feed }}\right)$ x persen Mol A

\section{c. $\Delta \mathrm{T}$ Bed Reactor}

$\Delta \mathrm{T}$ Bed Reactor adalah selisih antara temperatur masuk reaktor didalam bed dengan temperatur keluar pada $b e d$.

$$
\Delta \mathrm{T} \text { Bed Reactor }=\mathrm{T}_{\text {in reaktor }}-\mathrm{T}_{\text {out reactor }}(3)
$$

d. Catalyst Lifetime Rumus katalis lifetime digunakan untuk memperkirakan berapa lama umur dari katalis.

Catalyst Life Time $=$ volume Total Olefin Feed $\left(\mathrm{m}^{3}\right)$ (4)

Tabel 2. Komposisi Feed Reaktor 20-R-101 A

\begin{tabular}{|c|c|c|c|}
\hline \multirow{2}{*}{$\begin{array}{c}\text { Komposisi } \\
\text { (\%-Vol) }\end{array}$} & \multicolumn{3}{|c|}{ 20 Juli - 13 September 2016 } \\
\cline { 2 - 4 } & Max & Min & Avg \\
\hline $\mathrm{C}_{3}$ & 8.56 & 0 & 2.85 \\
\hline $\mathrm{C}_{3}=$ & 5.84 & 0 & 1.12 \\
\hline $\mathrm{i}-\mathrm{C}_{4}$ & 69,09 & 53.95 & 61.77 \\
\hline $\mathrm{n}^{-} \mathrm{C}_{4}$ & 87.77 & 1.42 & 3.12 \\
\hline $\mathrm{i}-\mathrm{C}_{4}=$ & 31.63 & 0 & 2.16 \\
\hline $1-\mathrm{C}_{4}=$ & 32.37 & 0 & 25.41 \\
\hline $\mathrm{Tr}^{-} \mathrm{C}_{4}=$ & 5.44 & 0.77 & 2.88 \\
\hline $\mathrm{Cis} \mathrm{C}_{4}=$ & 1.60 & 0.23 & 0.68 \\
\hline $1,3-\mathrm{C}_{4}=$ & 0 & 0 & 0 \\
\hline Olefin & 39.31 & 3.32 & 32.25 \\
\hline
\end{tabular}

Tabel 3. Komposisi Recycle feed Reactor 20-R-101A [5]

\begin{tabular}{|c|c|c|c|}
\hline \multirow{2}{*}{$\begin{array}{c}\text { Komposisi } \\
\text { (\%-Vol) }\end{array}$} & \multicolumn{3}{|c|}{20 Juli-13 September 2016} \\
\hline & Max & Min & Avg \\
\hline $\mathrm{C}_{3}$ & 16.96 & 0.72 & 5.61 \\
\hline $\mathrm{C}_{3}=$ & 5.18 & 0 & 0.77 \\
\hline $\mathrm{i}-\mathrm{C}_{4}$ & 91.70 & 55.95 & 79.84 \\
\hline $\mathrm{n}-\mathrm{C}_{4}$ & 8.54 & 1.47 & 3.95 \\
\hline $\mathrm{i}-\mathrm{C}_{4}=$ & 3.06 & 0 & 0.24 \\
\hline $1-\mathrm{C}_{4}=$ & 31.39 & 0.56 & 7.77 \\
\hline $\mathrm{Tr}-\mathrm{C}_{4}=$ & 3.99 & 0,11 & 1.44 \\
\hline $\mathrm{Cis}-\mathrm{C}_{4}=$ & 0.79 & 0.14 & 0.43 \\
\hline $1,3-\mathrm{C}_{4}=$ & 0 & 0 & 0 \\
\hline Olefin & 36.15 & 1.33 & 9.88 \\
\hline
\end{tabular}

Tabel 4. Kondisi Operasi reactor 20-R-101A [5]

\begin{tabular}{|c|c|c|c|}
\hline \multirow{2}{*}{ Parameter } & \multirow{2}{*}{ Unit } & \multicolumn{2}{|c|}{ Average } \\
\hline & & Aktual & Target \\
\hline Catalyst Life & $\mathrm{m}^{2} / \mathrm{kg}$ & 0,12 & 0,75 \\
\hline Fresh Feed & Ton/br. & 7,70 & $10-17,25$ \\
\hline Recycle & Ton/br. & 16,96 & $36 \max$ \\
\hline Total feed & Ton/br. & 24,66 & \\
\hline$\%$ volume Feed & \%wol & 32,25 & 77 \\
\hline \%volume Recycle & \%wol & 9,89 & 35,5 \\
\hline \%volume combined fesd & \%wol & 8,31 & 30 \\
\hline LHSV & $\mathrm{hx}-1$ & 1,14 & $1,10-1,96$ \\
\hline Feed Compexsion & $\%$-wt & 83,22 & 60 \\
\hline \multicolumn{4}{|l|}{ Reactor Temperature } \\
\hline Inlet $\mathrm{Rx}$ & ${ }^{\circ} \mathrm{C}$ & 138,23 & $145-155$ \\
\hline$\Delta \mathrm{T}$ at $\# 1$ bed & ${ }^{\circ} \mathrm{C}$ & 7,55 & $20 \max$ \\
\hline Inlet Temperature $\# 2$ & ${ }^{\circ} \mathrm{C}$ & 130,68 & $145 \mathrm{~min}$ \\
\hline$\Delta \mathrm{T}$ at $\# 2$ bed & ${ }^{\circ} \mathrm{C}$ & 24,54 & $20 \max$ \\
\hline Inlet Temperature $\# 3$ & ${ }^{\circ} \mathrm{C}$ & 131,23 & $145 \mathrm{~min}$ \\
\hline$\Delta \mathrm{T}$ at $\# 3$ bed & ${ }^{\circ} \mathrm{C}$ & 22,38 & $20 \max$ \\
\hline Inlet Temperature $\# 4$ & ${ }^{\circ} \mathrm{C}$ & 132,44 & $145 \mathrm{~min}$ \\
\hline$\Delta \mathrm{T}$ at $\# 4$ bed & ${ }^{\circ} \mathrm{C}$ & 18,31 & $20 \max$ \\
\hline Inlet Temperature $\# 5$ & ${ }^{\circ} \mathrm{C}$ & 131,28 & $145 \mathrm{~min}$ \\
\hline Outlet Rx & ${ }^{\circ} \mathrm{C}$ & 133,31 & $155-185$ \\
\hline$\Delta \mathrm{T}$ at $\# 5$ bed & ${ }^{\circ} \mathrm{C}$ & 2,03 & $20 \max$ \\
\hline \multicolumn{4}{|l|}{ Reactor Pressure } \\
\hline Inlet $\mathrm{Rx}$ & $\mathrm{kg} / \mathrm{cm}^{2} \mathrm{~g}$ & 32,92 & $36-37$ \\
\hline DP Rx & $\mathrm{kg} / \mathrm{cm}^{2} \mathrm{~g}$ & 2,13 & $3,5 \max$ \\
\hline
\end{tabular}


Yully Mulyani: Analisa Lifetime Katalis Pada Reactor Fix Bed di Catalytic Condensation Unit Light End Unit

Jurnal Migasian, e-issn : 2615-6695 / p-issn : 2580-5258

\section{METODOLOGI PENELITIAN}

Metode penelitian analisa lifetime katalis akan dibatasi pada perhitungan Kandungan Olefin didalam Feed, Recycle dan Combined Feed, Temperatur Inlet dan Delta Temperatur Bed Reaktor. Pressure Drop Reaktor dan LHSV, Catalyst Life Time, Kualitas Produk. yang didasarkan pada data-data aktual di lapangan.

Mengolah olefin khususnya butylene menjadi produk polygasoline melalui reaksi oligomerisasi. Jenis katalis yang di gunakan Solid Phosporus Acid (SPA)

Data primer digunakan sebagai dasar evaluasi dan analisa lifetime katalis pada reaktor di CCU yaitu : komposisi feed reactor, komposisi recycle feed reactor, kondisi Operasi reactor.

Data sekunder digunakan sebagai bahan perhitungan Lifetime katalis pada reaktor. Data ini diperoleh dari studi lapangan, wawancara Operator Data studi lapangan berupa kondisi operasi aktual reaktor di CCU pada Process Engineer.

a. LHSV ( Liquid Hourly Space Velocity )

b. Persen feed olefine

c. $\Delta \mathrm{T}$ Bed Reactor

d. Catalyst lifetime

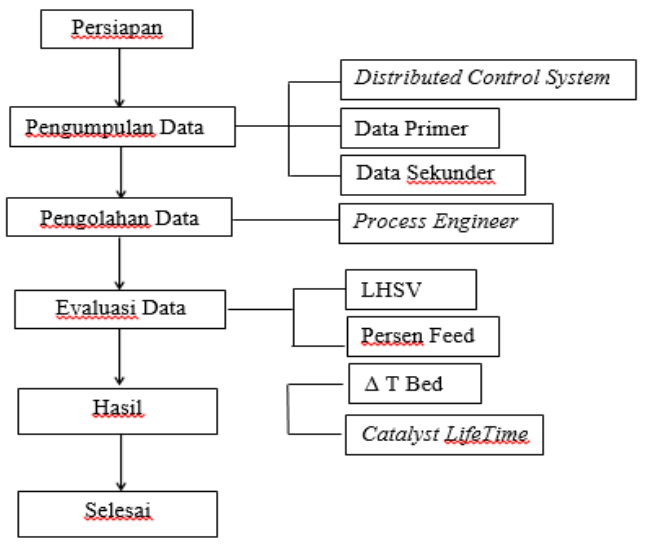

Gambar 1. Diagram Alir Penelitian

\section{HASIL DAN PEMBAHASAN}

\section{Kandungan Olefin di dalam Feed, Recycle dan Combined Feed}

Berikut ini merupakan kandungan olefin di dalam feed, Recycle dan combined feed:

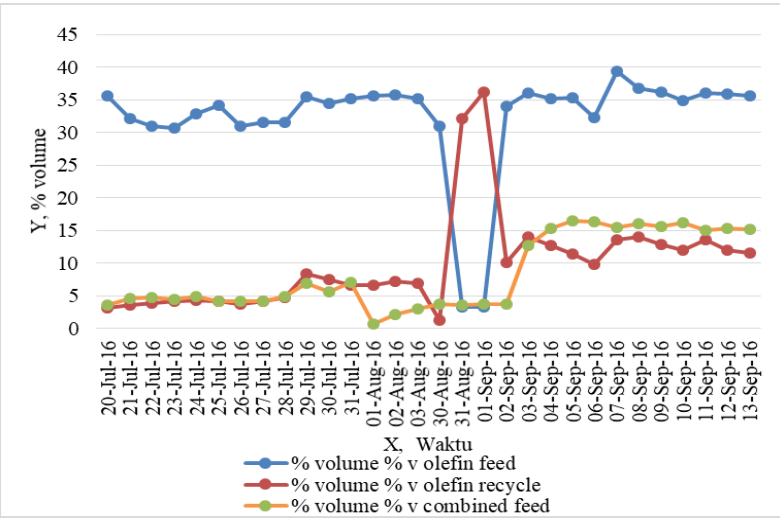

Gambar 2. Grafik kandungan olefin 20-R 101A

Pada Gambar 2 di atas menunjukkan kandungan olefin feed minimal 3,32\%-vol dan maksimal 39,31\%-vol, dengan rata-rata $32,25 \%$-vol, data desain kandungan olefin maksimal $77 \%$-vol pada feed. Sementara di dalam recycle 1,33 - 36,15\%-vol dengan rata-rata sebesar 9,89\%-vol. Kandungan olefin desain di dalam recycle adalah $35,5 \%$-vol. Kandungan olefin desain di dalam combined feed maksimal 30\%-vol. Kandungan olefin aktual dalam combined feed rata-rata $8,31 \%$-vol.

Pada Gambar 2, kandungan olefin masih di bawah batas desain dengan demikian persyaratan dari kandungan olefin di feed, recycle dan combined feed dapat terpenuhi. Apabila tidak terpenuhi akan menyebabkan laju konversi meningkat, hal ini dapat menyebabkan kenaikan beda temperatur dan beda tekanan pada bed reaktor dan memungkinkan terjadi reaksi 
pembentukan coke yang menyebabkan katalis rusak.

\section{Temperatur Inlet dan Delta Temperatur Bed Reaktor}

Temperatur Inlet Reaktor (RIT) berada pada rentang $128,99-142,58^{\circ} \mathrm{C}$ dengan rata-rata $138,23^{\circ} \mathrm{C}$.

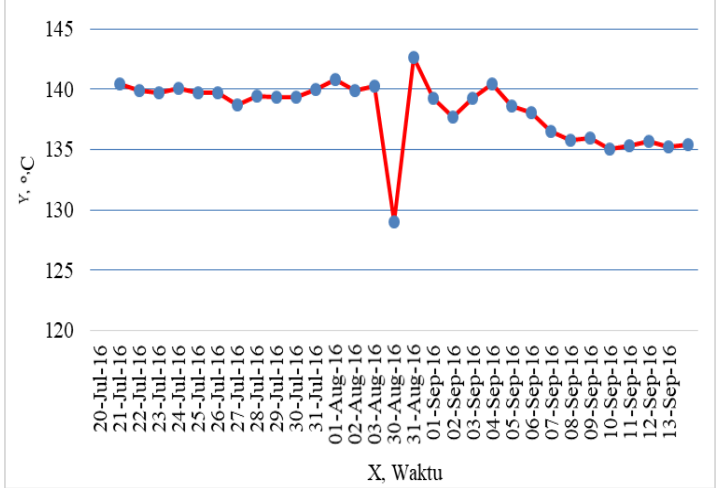

Gambar 3. Grafik Reaktor Temperatur inlet 20-R$101 \mathrm{~A}$

Pada Gambar 3, Kondisi temperatur inlet menuju reaktor 20-R-101 A ini ratarata berada sesuai dengan design awal yang diizinkan yaitu $130-145{ }^{0} \mathrm{C}$. Kondisi temperatur inlet dibawah design awal dapat mengakibatkan terjadinya reaksi esterifikasi antara olefin dengan asam fosfat yang ada dalam katalis. Hal ini dapat menyebabkan katalis melunak dan meningkatkan beda tekanan di dalam reaktor. Katalis yang melunak akan menggumpal sehingga dapat menurunkan konversi olefin.

Delta temperatur bed katalis menunjukkan tinggi rendahnya tingkat reaksi yang terjadi di bed reaktor. Reaksi yang terjadi bersifat eksotermis, dimana delta temperatur bed katalis linear dengan tingkat reaksi yang terjadi. Kenaikan delta temperatur bed katalis diikuti dengan peningkatan konversi feed dan kenaikan end point (reaksi oligomerasi yang berkelanjutan akan menyebabkan produk memiliki End Point yang tinggi).

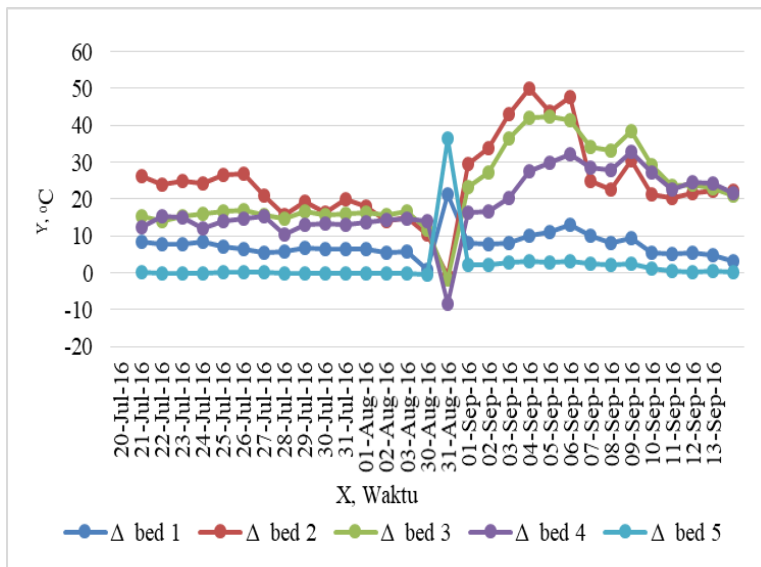

Gambar 4. Grafik $\Delta \mathrm{T}$ Reactor 20-R-101 A

Berdasarkan Gambar 4. Grafik hasil $\Delta \mathrm{T}$ Reactor 20-R-101 A diketahui bahwa pada bed 1 dan bed 5 beda temperaturnya masih kecil. Hal ini menunjukkan bahwa konversi olefin hanya sedikit terjadi pada bed 1 dan 5 . Konversi olefin yang banyak terjadi yaitu pada bed 2, 3 dan 4. Hal ini dilihat dari delta temperatur yang tinggi dibandingkan dengan bed 1 dan 5. Perbedaan temperatur yang di perbolehkan yaitu sebesar $20^{\circ} \mathrm{C}$, jika melebihi batas akan cenderung meningkat seiring bertambahnya hari operasi. Beda temperatur yang terlalu tinggi akan menyebabkan rusaknya katalis dan menyebabkan katalis mengalami dehidrasi sehingga menyebabkan kemampuanya untuk mempercepat laju reaksi akan berkurang.

\section{Pressure Drop Reaktor dan LHSV}

Kenaikan pressure drop terjadi karena reaksi konversi olefin yang berlebihan sehingga memicu pembentukan coke. Pressure drop $(\triangle \mathrm{P})$ reaktor design awal yaitu $3,5 \mathrm{~kg} / \mathrm{cm}^{2}$, dan grafik Pressure drop $(\Delta \mathrm{P})$ sebagai berikut : 
Yully Mulyani: Analisa Lifetime Katalis Pada Reactor Fix Bed di Catalytic Condensation Unit Light End Unit

Jurnal Migasian, e-issn : 2615-6695 / p-issn : 2580-5258

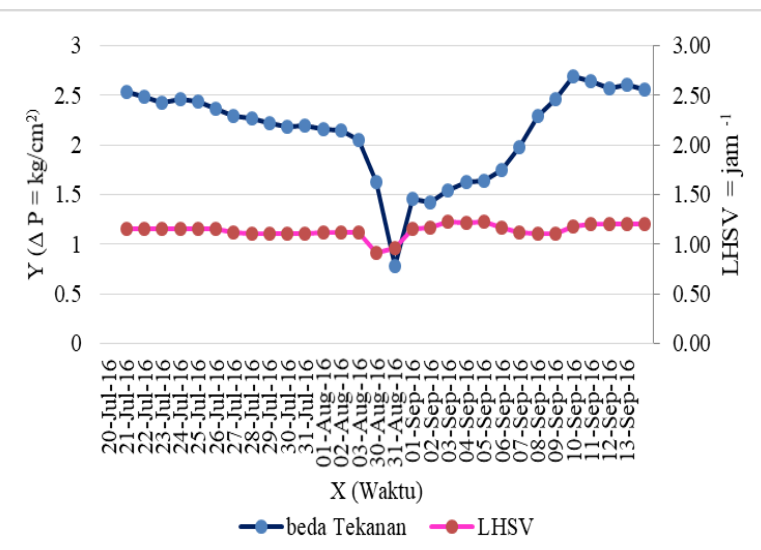

Gambar 5. Grafik Perbandingan beda Tekanan dan LHSV

Berdasarkan Gambar 5, bahwa pressure drop tertinggi sebesar $2,69 \mathrm{~kg} / \mathrm{cm}^{2}$, Untuk menurunkan pressure drop reaktor apabila melebihi batas yang ditentukan dapat dilakukan dengan dengan menurunkan LHSV (flow Fresh Feed dan Recycle Feed) dan juga membuka bypass reaktor yang juga akan menurunkan LHSV. LHSV adalah perbandingan volume per jam antara feed reactor dengan volume katalis di dalam reaktor. Pada range $0,92-1,23$ jam $^{-1}$ dengan rata-rata $1,14 \mathrm{jam}^{-1}$.

Minimum LHSV untuk Reaktor dijaga pada $0,9 \mathrm{jam}^{-1}$, dengan tujuan untuk mencegah adanya Channeling dan mengurangi waktu tinggal olefin di dalam reaktor. LHSV yang terlalu rendah akan mengakibatkan diperolehnya polimer berat, sehingga pembentukan coke bertambah yang akan menurunkan kualitas katalis. Maksimum LHSV pada umumnya tidak lebih dari $1,95 \mathrm{jam}^{-1}$ yang ditentukan oleh kemampuan menjaga konversi dan umur katalis, dan delta pressure reaktor. Kenaikan feed secara mendadak akan menimbulkan kenaikan beda tekanan secara tetap dan dapat menyebabkan beda tekanan melebihi batas toleransi yaitu $3,5 \mathrm{~kg} / \mathrm{cm}^{2}$ yang akan menyebabkan kerusakan katalis.

\section{Catalyst Lifetime}

Catalyst Lifetime memperkirakan umur katalis berdasarkan perhitungan-perhitungan yang sudah dihitung sebelumnya. Catalyst lifetime berguna untuk mengetahui kapan catalyst harus diganti agar produk yang dihasilkan maksimal.

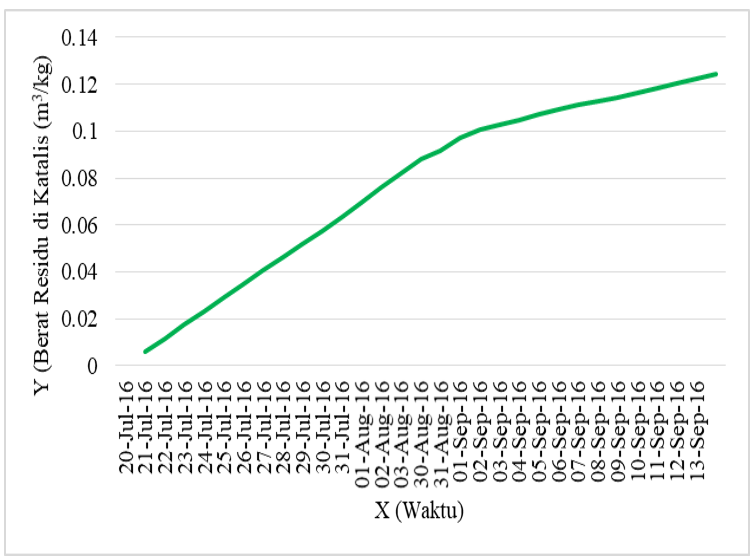

Gambar 6. Grafik Catalyst Lifetime

Dari Gambar 6, diketahui bahwa Catalyst lifetime di 20-R-101A dengan angka terakhir dari pengamatan pada tanggal 13 September 2016 mencapai $0,124 \mathrm{~m}^{3} / \mathrm{kg}$ dibandingkan dengan data design $0,75 \mathrm{~m}^{3} / \mathrm{kg}$. Apabila sudah mencapai $0,75 \mathrm{~m}^{3} / \mathrm{kg}$, maka katalis harus diganti agar produk yang dihasilkan tetap terjaga kualitasnya. Katalis biasanya diganti setiap 3 bulan penggunaan, namun pada kondisi lapangan bisa sampai 5 bulan dikarenakan pada bulan ke 3 - 5 katalis masih dapat digunakan secara optimal.

Tabel 5. Rata-Rata Kualitas Polygasoline

\begin{tabular}{|c|c|c|c|}
\hline Parameter & Satuan & persyaratan & rata-rata \\
\hline End point & ${ }^{\circ} \mathrm{C}$ & $205 \mathrm{max}$ & 200,66 \\
\hline RON & & $98 \mathrm{~min}$ & $>100$ \\
\hline RVP & Psig & $6,5 \mathrm{max}$ & 6,06 \\
\hline
\end{tabular}


Dari tabel di atas dapat diketahui bahwa rata-rata nilai end point dari produk polygasoline sebesar $201^{\circ} \mathrm{C}$ dengan syarat maksimal adalah $205^{\circ} \mathrm{C}$. Rata-rata RON adalah >100 dengan syarat minimal 98. Dan rata-rata RVP adalah 6,06 untuk syarat RVP maksimal 6,5 Psig.

\section{KESIMPULAN}

1. Produksi polygasoline masih dibawah design dengan rata-rata nilai end point dari produk polygasoline sebesar $201^{\circ} \mathrm{C}$ dengan syarat maksimal adalah $205^{\circ} \mathrm{C}$. Rata-rata RON adalah $>100$ dengan syarat minimal 98, rata-rata RVP adalah 6,06 Psig untuk syarat RVP maksimal 6,5 Psig, Variabel proses pada Catalytic Condensation Unit pada Konsentrasi Olefin Aktual feed sebesar 32,25\%, recycle 9,89\%, combine feed 8,31\%. LHSV Aktual 1,14 jam ${ }^{-1}$, Tekanan dan beda Tekanan Reaktor Aktual 32,92 $\mathrm{kg} / \mathrm{cm}^{2} ; 2,13 \mathrm{~kg} / \mathrm{cm}^{2}$, operator lapangan mengoptimalkan parameter yang ada di lapangan walaupun jauh dari nilai desain agar kualitas produk yang dihasilkan tetap terjaga.

2. Lifetime Katalis pada reactor fix bed diperoleh terakhir pada 13 September 2016 mencapai $0,124 \mathrm{~m}^{3} / \mathrm{kg}$ dari lifetime design $0,75 \mathrm{~m}^{3} / \mathrm{kg}$, katalis masih berada kondisi bagus pergantian katalis pada bulan ke $3-5$ katalis masih dapat digunakan secara optimal.

\section{UCAPAN TERIMA KASIH}

Terimakasih kepada Akamigas Balongan telah memberikan kesempatan dan tempat yang disediakan serta ilmu yang telah dibagikan selama penelitian ini berjalan.

\section{DAFTAR PUSTAKA}

[1] Dwi Lestari Yunita., 2011, "Kajian Tentang Deaktivasi Katalis", Universitas Negeri Yogyakarta.

[2] Harmiyanto, lilis., 2004, " Proses pengolahan migas, сери : pusdiklat Migas.

[3] Nob Hill publishing., 2016. Fixed Bed Catalitic Reactor.

[4] Pereira, Carmo J dan Tiberiu M. Leib., 2008. Perry's Chemical Engginers' Handbook. USA: The McGraw Hill Companies, Inc.

[5] Pertamina Exor-1.,1993.,Pedoman Operasi Kilang : Unit 20 Catalytic Condensation Unit. JGC Corporation \& Foster Wheeler (Indonesia) Limited.

[6] Winarno. 2003. Pengolahan Migas. Cepu: Pusdiklat Migas. 